\title{
Pancreatic cancer - More familial than you thought
}

\author{
M. Tascilar ${ }^{\text {a }}$, A.C. Tersmette ${ }^{\text {a }}$, G.J.A. Offerhaus ${ }^{\text {a }}$ \\ and R.H. Hruban ${ }^{b, *}$ \\ a Department of Pathology, the Academic Medical \\ Center, Amsterdam, The Netherlands \\ ${ }^{\mathrm{b}}$ The Departments of Pathology and Oncology, \\ The Johns Hopkins Medical Institutions, Baltimore, \\ $M D, U S A$
}

Received 23 October 1999

Accepted 6 January 2000

\section{Introduction}

Although pancreatic cancer accounts for only $2 \%$ of new cancer cases, it is the fifth leading cause of cancerrelated death in Western countries. The high mortality rate is mainly caused by the fact that most cases are detected at a stage when curable resection is not an option anymore and prognosis is poor [45,55].

The etiology of pancreatic cancer is poorly understood. Several putative risk factors have been described, such as cigarette smoking, high-fat diet, chronic pancreatitis, diabetes mellitus and remote history of partial gastrectomy [3,20,23,28,36,38,52,59]. Of these cigarette smoking has the strongest positive association with pancreatic cancer.

Recently, it has been suggested that a family history of pancreatic cancer is a risk factor for pancreatic cancer, and Henry Lynch has estimated that as many as $10 \%$ of pancreatic cancers are familial [32]. There have been a number of isolated case reports of the aggregation of pancreatic cancer in families suggesting a hereditary susceptibility for pancreatic cancer, however chance aggregations or shared environmental exposure could also cause this clustering $[8,35,44]$.

*Correspondence to: Ralph H. Hruban, MD, Johns Hopkins Hospital, Weinberg Building, Room 2242, Baltimore, MD 21287, USA. E-mail: rhruban@jhmi.edu.
In order to overcome the problems caused by the small numbers inherent to case reports, several groups have studied extended families with pancreatic cancer clustering and these studies have suggested an autosomal dominant pattern of inheritance to the pancreatic cancers in some of these families [1,7,18,32,34]. The pathology, sex-ratio, age of onset and prognosis of these patients were comparable to patients with sporadic pancreatic cancer [34].

In addition, several registries have been established to learn more about the role of inheritance in the etiology of pancreatic cancer. These include the National Familial Pancreatic Tumor Registry (NFPTR), established at The Johns Hopkins University, Baltimore, USA in 1994 (http://pathology.jhu.edu/pancreas), and the European Registry for Hereditary Pancreatitis and Pancreatic Cancer (EUROPAC) of the European Study Group for Pancreatic Cancer (ESPAC) [11,18].

Detailed examination of the pancreatic cancer-prone families in these registries has yielded important information on the epidemiology and genetics of this disease. DNA from these individuals can be used for genetic linkage, molecular genetics and finally cloning of a putative cancer causing gene. If a gene is identified as responsible for the familial aggregation of pancreatic cancer, it could form the basis for the development of a screening program for pancreatic cancer and eventually gene-based therapies.

\section{The National Familial Pancreatic Tumor Registry (NFPTR)}

To date, more than 446 families have been registered in the NFPTR. In this registry "familial pancreatic cancer" is defined as pedigrees in which two or more first degree relatives are affected with pancreatic cancer. The term "sporadic pancreatic cancer" is used to designate those families without two affected first-degree 
relatives. In a preliminary analysis, we prospectively followed 153 familial pancreatic cancer families from this registry looking at new cancers in family members who were healthy at the time of entry into the registry [41]. Remarkably, we observed a 18-fold increased risk of pancreatic cancer in the 1100 first degree relatives of patients with pancreatic cancer. This risk of apparently healthy family members prospectively developing pancreatic cancer increased to 57-fold if three or more family members had pancreatic cancer at the time of entry into the registry.

There was no obvious relationship with smoking behaviour.

This preliminary analysis shows that the risk of pancreatic cancer is indeed considerably increased among first degree relatives in families in which at least two first degree relatives had previously developed pancreatic cancer. Moreover, the incidence of non-pancreatic cancer, such as breast, colon and lung cancer, also appears to be increased in these families [18]. In a recent report Vaittinen et al. confirmed the abovementioned association between pancreatic cancer and various other cancers in an analysis of familial risks in discordant cancers of offspring and parents using the Swedish nation-wide Family-Cancer Database [54].

Importantly, these data strongly support the hypothesis that there is a genetic basis for the aggregation of pancreatic cancer in some families.

\section{Genetic alterations in sporadic pancreatic cancer}

A large number of genes have been identified which play a role in the formation of sporadic pancreatic cancer. These genes are important for our understanding of familial pancreatic cancer, because, as Knudson described years ago for retinoblastoma, the same genes are often responsible for familial and sporadic forms of a cancer [24,25]. Germline mutations in some of the genes that are known to play a role in the sporadic pancreatic carcinogenesis appear to play a role in the development of some familial pancreatic cancers.

The genes which have been shown to play a role in the development of sporadic pancreatic cancer include oncogenes, tumor suppressor genes and DNA mismatch repair genes. Activating point mutations in the K-ras oncogene are one of the most common genetic alteration in sporadic pancreatic cancer, 80-90\% of the sporadic pancreatic cancers harbour activating point mutations in the K-ras oncogene [19].
Several tumor suppressor genes have also been described to be inactivated in sporadic pancreatic cancer. The p53 tumor suppressor is inactivated in 50-70\%, the deleted in pancreatic cancer 4 (DPC4/SMAD4) gene is inactivated in approximately $55 \%$, and the p16/MTS-1 gene is inactivated in approximately $95 \%$ of pancreatic cancers $[9,46,47]$. The BRCA2 gene is inactivated in a small fraction (5-10\%) of apparently sporadic pancreatic cancers, and the STK11 gene, responsible for the Peutz-Jeghers syndrome, and the $M K K 4$ gene are inactivated in a small (approximately $4 \%$ ) proportion of pancreatic cancers $[13,15,39,50]$.

Finally, DNA mismatch repair genes appear to be inactivated in a small fraction $(\sim 4 \%)$ of pancreatic cancers. These cancers are remarkable because they appear to have a distinct histologic appearance ("medullary phenotype") and they are often wild-type for the K-ras gene [14].

\section{Genetic alterations in familial pancreatic cancer}

Some of the genetic alterations responsible for the aggregation of pancreatic cancer in families have already been identified and in all cases the genes known to be targeted are the same genes targeted in sporadic pancreatic cancer. These genetic alterations establish a genetic basis for the familial aggregation of pancreatic cancer and other tumor types in some families.

\subsection{P16/MTS-1 gene}

As mentioned above, the $p 16$ tumor suppressor gene is inactivated in a very high percentage $(\sim 95 \%)$ of sporadic pancreatic cancers. In these sporadic cancers the pl6 gene is inactivated either by homozygous deletions (in $40 \%$ of the carcinomas), by mutation of one allele combined with loss of the other allele (in $40 \%$ ), or by hypermethylation of the $p 16$ promotor region $(\sim 15 \%)$ [47].

Germline mutations in the $p 16$ gene are responsible for the development of the Familial Atypical Multiple Mole Melanoma (FAMMM) syndrome, a rare disorder which predisposes affected patients to the development of multiple nevi, melanomas and pancreatic cancer [16,33,34]. Goldstein et al. [16] have demonstrated that germline mutations in the pl6 gene, which impaired the $p 16$ protein function in in vitro assays, are associated with a 22-fold increased risk of developing pancreatic cancer in melanoma-prone families. 
Moskaluk et al. [37] have recently postulated that mutations affecting the C-terminal end of the 16 protein are associated with a higher penetrance of pancreatic cancer. Now that the gene responsible for the clustering of melanoma and pancreatic cancer in some families has been identified, families with a strong aggregation of pancreatic cancer and melanoma can be tested for germline mutations in the $p 16$ gene. Careful surveillance of those members with a germline mutation in the p16 gene should stimulate the development of techniques for early diagnosis for this high risk group and thereby improving survival.

\subsection{STK11/LKB1 gene}

Germline mutations in the STK11/LKB1 gene have recently been shown to cause the Peutz-Jeghers syndrome (PJS) [17,22]. PJS is a rare syndrome characterized by hamartomatous polyposis of the gastrointestinal tract and by the occurrence of melanin spots on the buccal mucosa and on the lips [21,42]. The Peutz-Jeghers syndrome has been associated with an increased risk of developing cancer, including pancreatic cancer [13].

$\mathrm{Su}$ et al. recently reported inactivation of the STK11/ $L K B 1$ gene in 5-6\% of the 135 sporadic pancreatic and biliary carcinomas they analyzed. In these cancers, the $S T K 11 / L K B 1$ gene was inactivated by either homozygous deletions or intragenic sequence mutations combined with loss of the other allele [51]. They also studied a pancreatic cancer obtained from a PJS patient who died from pancreatic cancer and they demonstrated a germline splice site mutation in the STK11/LKB1 gene in the patient's germline DNA and a loss of the wild type allele in the patient's pancreatic cancer. The $S T K 11 / L K B 1$ gene was thereby inactivated in this patient's cancer. Thus, just as is true for $p 16$, genetic alterations in the $S T K 1 / / L K B 1$ gene contribute to the development of sporadic cancer, and when present in the germline, these alterations may also play a role in the development of familial pancreatic cancer.

\subsection{BRCA2 gene}

As mentioned previously, an increased risk for developing breast cancer has been observed in families in which there is an aggregation of pancreatic cancer [18]. Conversely, it is shown that, in families of patients with breast cancer there is an increased risk of developing pancreatic cancer [53].
Germline mutations in the BRCA2 gene may explain these associations. Indeed, pancreatic cancers have been reported in many of the BRCA2 kindred [2, 39]. The increased risk of pancreatic cancer caused by $B R C A 2$ is not limited, however, to these classical $B R C A 2$ kindred.

Approximately $7 \%$ of the patients with apparently sporadic pancreatic cancers analyzed by Goggins et al. had a germline mutation in the BRCA2 gene, and Goggins et al. demonstrated that the remaining wild-type allele was lost in the pancreatic cancers that developed in these patients. Remarkably, only one of the five patients with pancreatic cancer and germline BRCA2 mutations had a family history positive for breast cancer and none of them had a positive family history of pancreatic cancer [15]. The penetrance of this trait is therefore probably low and the inherited basis for some patients with pancreatic cancer would be missed if it were not for our knowledge of this gene.

To date these germline mutations in the BRCA2 gene are the most frequent described cause of an inherited predisposition to pancreatic cancer. It may prove useful to screen members of families in which there is an aggregation of breast and pancreatic cancer for the presence of germline mutations in the BRCA2 gene. Those found to carry a germline mutation may benefit of breast cancer screening.

\subsection{Cationic trypsinogen gene}

Pancreatic cancer clustering is also seen in families with a hereditary form of pancreatitis $[6,10]$. Hereditary pancreatitis is an autosomal dominant disorder caused by point mutations in the cationic trypsinogen gene, PRSS1, on chromosome 7q35 [56,57]. These mutations result in a cationic trypsinogen protein which is resistant to auto-inactivation, ultimately resulting in autodigestion of the pancreas. Affected patients have recurrent episodes of pancreatitis that often begin during childhood. Compared with the general population and patients who have chronic pancreatitis of common etiologies who have a somewhat increased cancer risk, patients with hereditary pancreatitis have a cumulative risk of developing pancreatic carcinoma that approaches $40 \%$ by the age of 70 . The relative risk for the development of pancreatic carcinoma is approximately 50-fold, and the average age of onset is dramatically reduced to 39 years [29].

Considering the high lifetime risk of pancreatic cancer in this group, it is important to recognize patients with hereditary pancreatitis in an early stage, making surveillance of these patients and maybe even prophylactic pancreatectomy an option. 


\subsection{The Hereditary Non-Polyposis Colorectal Cancer Syndrome (HNPCC)}

The Hereditary Non-Polyposis Syndrome (HNPCC) is the result of a germline mutation in one of the DNA mismatch repair genes $[12,14,26,27,40,49]$. Tumors which develop in patients who have a germline mutation in one of the DNA mismatch repair genes show microsatellite instability, which is a change in length of repeated DNA sequences. In a study performed by Goggins et al. [14] approximately $4 \%$ of the 82 analyzed pancreatic cancers showed microsatellite instability; these pancreatic cancers appeared to have a distinct, medullary histology. Wilentz et al. [58] followed up on the report by Goggins et al. and demonstrated that pancreatic cancers with a medullary phenotype type were significantly associated with a family history of any cancer in a first-degree relative. Of note, one of the patients included in this study had synchronous pancreatic and colon cancers, which showed microsatellite instability, suggesting that he has HNPCC. Together with the finding that in familial pancreatic cancer kindreds there is an increased risk of colon cancer, these data indicate that HNPCC can be the cause of pancreatic cancer in at least some of the kindreds in which there is a clustering of colon and pancreatic cancer [18].

\subsection{Other syndromes}

Several other inherited syndromes have been suggested to be associated with pancreatic cancer. These include the familial adenomatous polyposis syndrome (FAP), ataxia telangiectasia, Multiple Endocrine Neoplasia 1 (MEN1) syndrome, and glucanoma syndrome $[4,31,44,48]$.

\section{Conclusion}

This last decade has seen a dramatic advance in our understanding of familial pancreatic cancer. The prospective development of new pancreatic cancers in familial pancreatic kindred firmly establishes that "familial pancreatic cancer" is a real entity, and a number of the genes responsible for the familial aggregation of pancreatic cancer have already been identified. Furthermore, as our experience with $B R C A 2$ has taught us, even some pancreatic cancers which appear sporadic, may in fact be caused by inherited genetic defects.
The genetic alterations which have been associated with familial pancreatic cancer include germline mutations in p16, STK11, BRCA2, PRSS1, and in the DNA mismatch repair genes. Screening of individuals for the presence of one of these germline mutation can now be performed when indicated by the family cancer history.

Members of families in which there is an aggregation of pancreatic cancer will also benefit from efforts to develop a new screening test for early pancreatic cancer. At present, screening for familial pancreatic cancer can be approached only at a clinical level. The use of endoscopic ultrasound (EUS), magnetic resonance imaging (MRI), ERCP, and even molecular analysis of brush cytology and pancreatic juice obtained during ERCP may all be of value, but the efficiency of each technique needs to be established in this patient population [5].

\section{References}

[1] C.E. Aston, M.G. Banke, P.J. McNamara et al., Segregation analysis of pancreatic cancer (Abstract), Am. J. Hum. Genet. 61 (1997), A194

[2] D.B. Berman, J. Costalas, D.C. Schultz, G. Grana, M. Daly and A.K. Godwin, A common mutation in BRCA2 that predisposes to a variety of cancers is found in both Jewish Ashkenazi and non-Jewish individuals, Cancer Res. 56 (1996), 3409-3414.

[3] M. Binstock, D. Krakow, J. Stamler, J. Reiff, V. Persky, K. Liu and D. Moss, Coffee and pancreatic cancer: An analysis of international mortality data, Am. J. Epidemiol. 118 (1983), 630640.

[4] G. Boden and O.E. Owen, Familial hypergluconemia, an unusual dominant disorder, N. Engl. J. Med. 296 (1977), 634-638.

[5] T.A. Brentnall, M.P. Bronner, D.R. Byrd, R.C. Hadgitt and M.B. Kimmey, Early diagnosis and treatment of pancreatic dysplasia in patients with a family history of pancreatic cancer, Ann. Intern. Med. 131 (1999), 247-255.

[6] M.W. Comfort and A.G. Steinberg, Pedigree of a family with hereditary chronic relapsing pancreatitis, Gastroenterol. 21 (1952), 54-63.

[7] K.E. Crowley et al., Familial aggregation of other cancers in families with pancreatic cancer (Abstract), Am. J. Hum. Genet. 61 (1997), A196.

[8] N. Dat and S. Sontag, Pancreatic carcinoma in brothers, Ann. Intern. Med. 97 (1982), 282.

[9] J.A. DiGiuseppe, R.H. Hruban, S.N. Goodman, M. Polak, F.M. van den Berg, D.C. Allison, J.L. Cameron and G.J. Offerhaus, Overexpression of p53 protein in adenocarci noma of the pancreas, Am. J. Clin. Pathol. 101 (1994), 684-688.

[10] M. de la Garza, I.D. Hill, E. Lebenthal, V.L.W. Go, E.P. DiMango, J.D. Gardner, E. Lebenth, A. Scheele, eds, The Pancreas: Biology, Pathobiology, and Disease, 2nd edn, Raven, New York, NY, 1993, p. 1095. 
[11] M.D. Finch, N. Howes, I. Ellis, R. Mountford, R. Sutton, M. Raraty and J.P. Neoptolemos, Hereditary pancreatitis and familial pancreatic cancer, Digestion 58 (1997), 564-569.

[12] R. Fishel, M.K. Lescoe, M.R.S. Rao, N.G. Copeland, N.A. Jenkins, J. Garber, M. Kane and R. Kolodner, The human mutator gene homolog MSH2 and its asociation with hereditary nonpolyposis colon cancer, Cell 75 (1993), 1027-1038.

[13] F.M. Giardiello, S.B. Welsh, S.R. Hamilton, G.J. Offerhaus, A.M. Gittelsohn, S.V. Booker, A.J. Krush, J.H. Yardley and G.D. Luk, Increased risk of cancer in Peutz-Jeghers syndrome, N. Engl. J. Med. 316 (1987), 1511-1514.

[14] M. Goggins, G.J.A. Offerhaus, W. Hilger, C.A. Griffin, M. Shekher, D. Tang, T.A. Sohn, C.J. Yeo, S.E. Kern and R.H. Hruban, Pancreatic adenocarcinomas with DNA replication errors (RER+) are associated with wild-type K-ras and characteristic histopathology: poor differentiation, a syncytial growth pattern, and pushing borders suggest RER+, Am. J. Pathol. 152 (1998), 1501-1507.

[15] M. Goggins, M. Schutte, J. Lu, C.A. Moskaluk, C.L. Weinstein, G.M. Petersen, C.J. Yeo, C.E. Jackson, H.T. Lynch, R.H. Hruban and S.E. Kern, Germline BRCA2 gene mutations in patients with apparently sporadic pancreatic carcinomas, Cancer Res. 56 (1996), 5360-5364.

[16] A.M. Goldstein et al., Increased risk of pancreatic cancer in melanoma-prone kindreds with p16INK4 mutations, N. Engl. J. Med. 333 (1995), 970-974.

[17] A. Hemminki et al., A serine/threonine kinase gene defective in Peutz-Jeghers syndrome, Nature 391 (1998), 184-187.

[18] R.H. Hruban, G.M. Petersen, P.K. Ha and S.E. Kern, Genetics of pancreatic cancer. From genes to families, Surg. Oncol. Clin. N. Am. 7 (1998), 1-23.

[19] R.H. Hruban, A.D. van Mansfeld, G.J. Offerhaus, D.H. van Weering, D.C. Allison, S.N. Goodman, T.W. Kensler, K.K. Bose, J.L. Cameron and J.L. Bos, K-ras oncogene activation in adenocarcinoma of the human pancreas. A study of 82 carcinomas using a combination of mutant-enriched polymerase chain reaction analysis and allele-specific oligonucleotide hybridization, Am. J. Path. 143 (1993), 545-554.

[20] International Agency for Research on Cancer. IARC Monographs of the Evaluation of the Carcinogenic Risk of Chemicals to Man, Tobacco Smoking, Vol. 38, IARC, Lyon, France, 1986, pp. 279-282.

[21] H. Jeghers, V.A. McKusick and K.H. Katz, Generalized intestinal polyposis and melanin spots of the oral mucosa, lips and digits, N. Engl. J. Med. 241 (1949), 993-1031.

[22] D.E. Jenne, H. Reimann, J. Nezu, W. Friedel, S. Loff, R. Jeschke, O. Müller, W. Back and M. Zimmer, Peutz-Jeghers syndrome is caused by mutations in a novel serine threonine kinase, Nat. Genet. 18 (1998), 38-43.

[23] A. Karmody and J. Kyle, The association between carcinoma of the pancreas and diabetes mellitus, Br. J. Surg. 56 (1969), 362-364.

[24] A.G. Knudson, Hereditary cancer, oncogenes, and antioncogenes, Cancer Res. 45 (1985), 1437-1443.

[25] A.G. Knudson, Hereditary cancer: two hits revisited, J. Cancer Res. Clin. Oncol. 122 (1996), 135-140.

[26] T.A. Kunkel, Slippery DNA and diseases, Nature 365 (1993), 207-208.
[27] F.S. Leach et al., Mutations of a mutS homolog in hereditary nonpolyposis colorectal cancer, Cell 75 (1993), 1215-1236.

[28] A.B. Lowenfels, P. Maisonneuve, G. Cavallini, R.W. Ammann, P.G. Lankisch, J.R. Andersen, E.P. Dimagno, A. AndrenSandberg and L. Domellof, Pancreatitis and the risk of pancreatic cancer. International Pancreatitis Study Group, N. Engl. J. Med. 328 (1993), 1433-1437.

[29] A.B. Lowenfells, P. Maisonneuve, E.P. DiMagno, Y. Elitsur, L.K. Gates, Jr., J. Perrault and DC. Whitcomb, Hereditary pancreatitis and the risk of pancreatic cancer: International Hereditary Pancreatitis Study Group, J. Natl. Cancer. Inst. 89 (1997), 442-446.

[30] J.A. Lumadue, C.A. Griffin, M. Osman and R.H. Hruban, Familial pancreatic cancer and the genetics of pancreatic cancer, Surg. Clin. North. Am. 75 (1995), 845-855

[31] H.T. Lynch, Genetics and pancreatic cancer, Arch. Surg. 129 (1994), 266-268.

[32] H.T. Lynch, M.L. Fitzsimmons, T.C. Smyrk, S.J. Lanspa, P. Watson, J. McClellan and J.F. Lynch, Familial pancreatic cancer: clinicopathologic study of 18 nuclear families, Am. $J$. Gastroenterol. 85 (1990), 54-60.

[33] H.T. Lynch and R.M. Fusaro, Pancreatic cancer and the familial atypical multiple mole melanoma (FAMMM) syndrome, Pancreas 6 (1991), 127-131.

[34] H.T. Lynch, T. Smyrk, S.E. Kern, R.H. Hruban, C.J. Lightdale, S.J. Lemon, J.F. Lynch, L.R. Fusaro, R.M. Fusaro and P. Ghadirian, Familial pancreatic cancer: A review, Semin. Oncol. 23 (1996), 251-275.

[35] R.P. MacDermott and P. Kramer, Adenocarcinoma of the pancreas in four siblings, Gastroenterol. 65 (1973), 137-139.

[36] A. Marble, Diabetes and cancer, N. Engl. J. Med. 211 (1954), 339-349.

[37] C.A. Moskaluk, R.H. Hruban, A. Lietman, T. Smyrk, L. Fusaro, R. Fusaro, J. Lynch, C.J. Yeo, C.E. Jackson, H.T. Lynch and S.E. Kern, Low prevalence of $\mathrm{p} 16^{\mathrm{ink} 4 \mathrm{a}}$ and CDK4 mutations in familial pancreatic carcinoma, Hum. Mut. 12 (1998), 70.

[38] G.J. Offerhaus, F.M. Giardiello, G.W. Moore and A.C. Tersmette, Partial gastrecto my: A risk factor for carcinoma of the pancreas?, Hum. Pathol. 18 (1987), 285-288.

[39] H. Ozcelik, Germline BRCA2 6174delT mutations in Ashkenazi Jewish pancreatic cancer patients, Nat. Genetics 16 (1997), 17-18

[40] R. Parsons, G.-M. Li, M.J. Longley, W.-H. Fang, N. Papadopoulos, J. Jen, A. de la Chapelle, K.W. Kinzler, B. Vogelstein, P. Modrich, Hypermutability and mis match repair deficiency in RER+ tumor cells, Cell 75 (1993), 1227-1236.

[41] G.M. Petersen, A.C. Tersmette, F. Falatko et al., High rate of incident pancreatic cancers among at-risk relatives in familial pancreatic cancer, Presented at 7th SPORE Investigator's Workshop, July 11-13, 1999, Rockville, MD, 1999, unpublished.

[42] J.L.A. Peutz, Over een zeer merkwaardige, gecombineerde familiaire polyposis van de slijmvliezen van den tractus intestinalismet die van de neuskeelholte en gepaard met eigenaardige pigmetaties van de huid en slijmvliezen, Nederlands Maandschrift voor Geneeskunde 10 (1921), 134-136. 
[43] M. Pipeleers-Marichal et al., Gastrinomas in the duodenum of patients with multiple endocrine neoplasia type 1 and the Zollinger-Ellison syndrome, N. Engl. J. Med. 322 (1990), 723727.

[44] R. Reimer, J.F. Fraumeni, Jr., R.F. Ozols and R. Bender, Pancreatic cancer in father and son, Lancet 1 (1977), 911-912.

[45] S. Rosewicz and B. Wiedenmann, Pancreatic carcinoma, The Lancet 349 (1997), 485-489.

[46] E. Rozenblum, M. Schutte, M. Goggins, S.A. Hahn, S. Panzer, M. Zahurak, S.N. Goodman, T.A. Sohn, R.H. Hruban, C.J. Yeo and S.E. Kern, Tumorsuppressive pathways in pancreatic carcinoma, Cancer Res. 57 (1997), 1731-1734.

[47] M. Schutte, R.H. Hruban, J. Geradts, R. Maynard, W. Hilgers, S.K. Rabindran, C.A. Moskaluk, S.A. Hahn, I. SchwarteWaldhoff, W. Schmiegel, S.B. Baylin, S.E. Kern and J.G. Herman, Abrogation of the Rb/p16 tumor-suppressive pathway in virtually all pancreatic carcinomas, Cancer Res. 57 (1997), 3126-3130.

[48] A.D. Spigelman, K.C. Farmer, M. James, P.I. Richman and R.K. Phillips, Tumours of the liver, bile ducts, pancreas and duodenum in a single patient with familial adenomatous polyposis, Br. J. Surg. 78 (1991), 979-980.

[49] M. Strand, T.A. Prolla, R.M. Liskay and T.D. Petes, Destabilization of tracts of simple repetitive DNA in yeast by mutations affecting DNA mismatch, Lett. Nat. 365 (1993), 274-276.

[50] G.H. Su, W. Hilgers, M.C. Shekher, D.J. Tang, C.J. Yeo, R.H. Hruban and S.E. Kern, Alterations in pancreatic, biliary and breast carcinomas support MKK4 as a genetically targeted tumor suppressor gene, Cancer Res. 58 (1998), 2339-2342.

[51] G.H. Su, R.H. Hruban, R.K. Bansal, G.S. Bova, D.J. Tang, M.C. Shekher, A.M. Westerman, M.M. Entius, M. Goggins,
C.J. Yeo and S.E. Kern, Germline and somatic mutations of the STK11/LKB1 Peutz-Jeghers gene in pancreatic and biliary cancers, Am. J. Pathol. 154 (1999), 1835-1840.

[52] A.C. Tersmette, G.J.A. Offerhaus, F.M. Giardiello, K.W.F. Tersmette, J.P. Vanderbroucke and G.N.J. Tytgat, Occurrence of non-gastric cancer in the digestive tract after remote partial gastrectomy: analysis of an Amsterdam cohort, Int. J. Cancer 46 (1990), 792-795.

[53] H. Tulinius, G.H. Olafsdottir, H. Sigvaldason, L. Tryggvadottir, K. Bjarnadottir, Neoplastic diseases in families of breast cancer patients, J. Med. Genet. 31 (1994), 618-621.

[54] P. Vaittinen and K. Hemminki, Familial cancer risks in offspring from discordant parental cancers, Int. J. Cancer 81 (1999), 12-19.

[55] A.L. Warshaw and C. Fernandez-Del Castillo, Pancreatic carcinoma, N. Engl. J. Med. 326 (1992), 455-465.

[56] D.C. Whitcomb et al., Hereditary pancreatitis is caused by a mutation in the cationic trypsinogen gene, Nat. Genet. 14 (1996), 141-145.

[57] D.C. Whitcomb et al., A gene for hereditary pancreatitis maps to chromosome 7q35, Gastroenterol. 110 (1996), 1975-1980.

[58] R.E. Wilentz et al., Genetic, immunohistochemical, and clinical features of medullary carcinomas of the pancreas: a newly described and characterized entity, Am. J. Pathol. (2000), in press.

[59] E.L. Wynder, K. Mabuchi, N. Maruchi and J.G. Fortner, Epidemiology of cancer of the pancreas, J. Natl. Cancer Inst. 50 (1973), 645-667. 


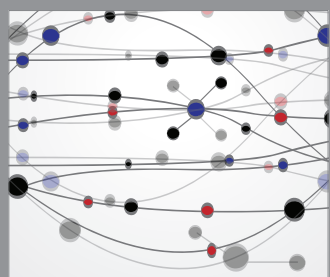

The Scientific World Journal
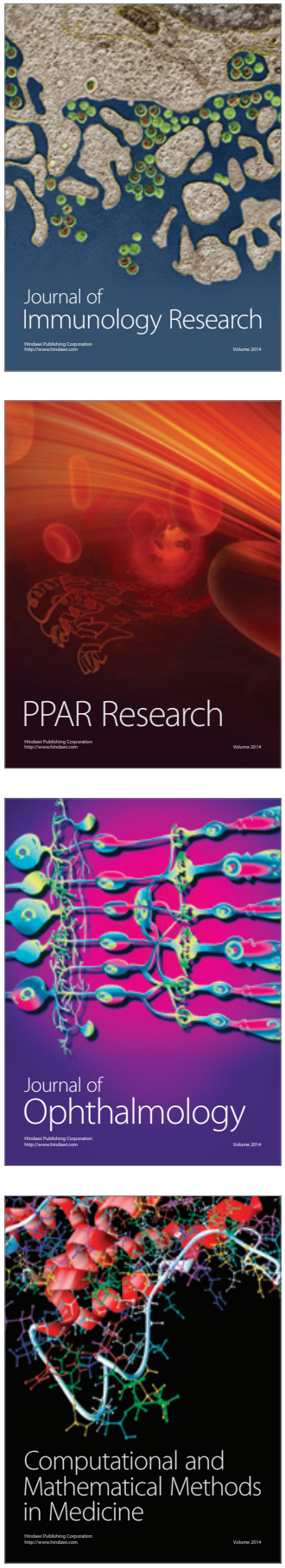

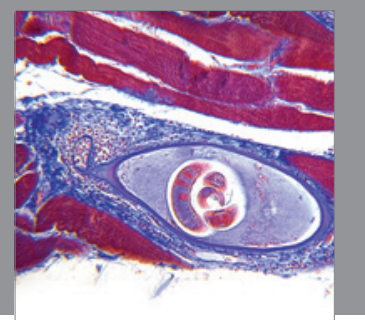

Gastroenterology

Research and Practice
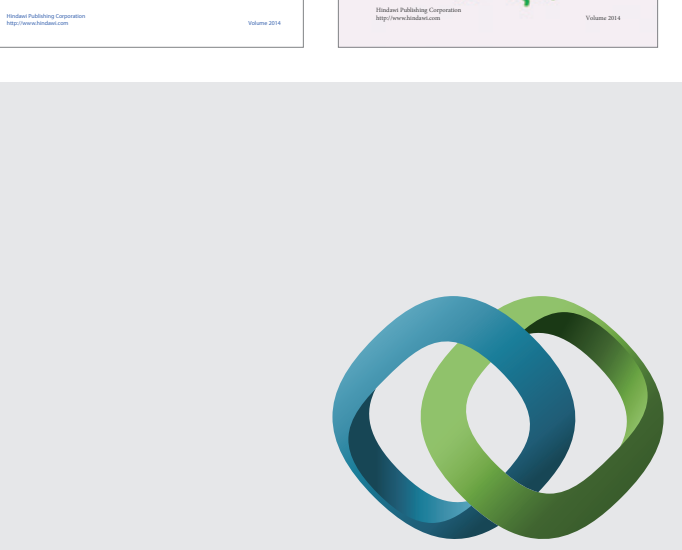

\section{Hindawi}

Submit your manuscripts at

http://www.hindawi.com
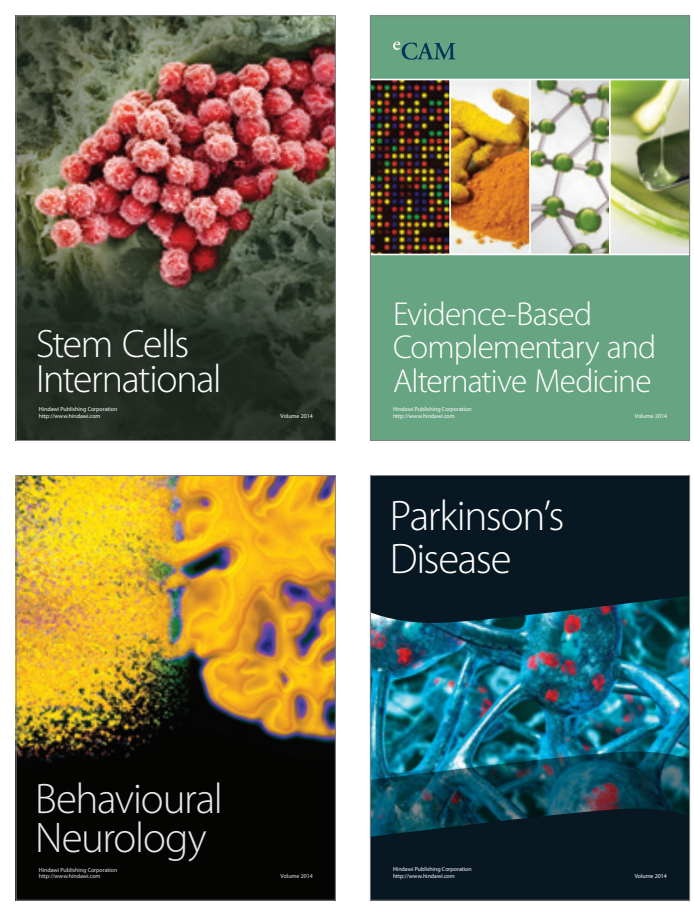

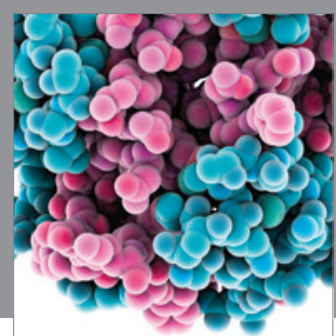

Journal of
Diabetes Research

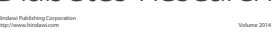

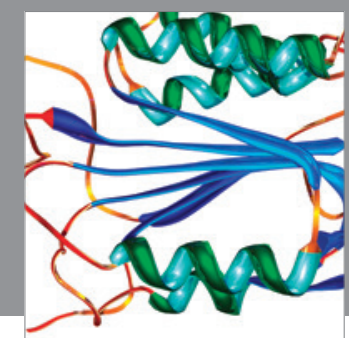

Disease Markers
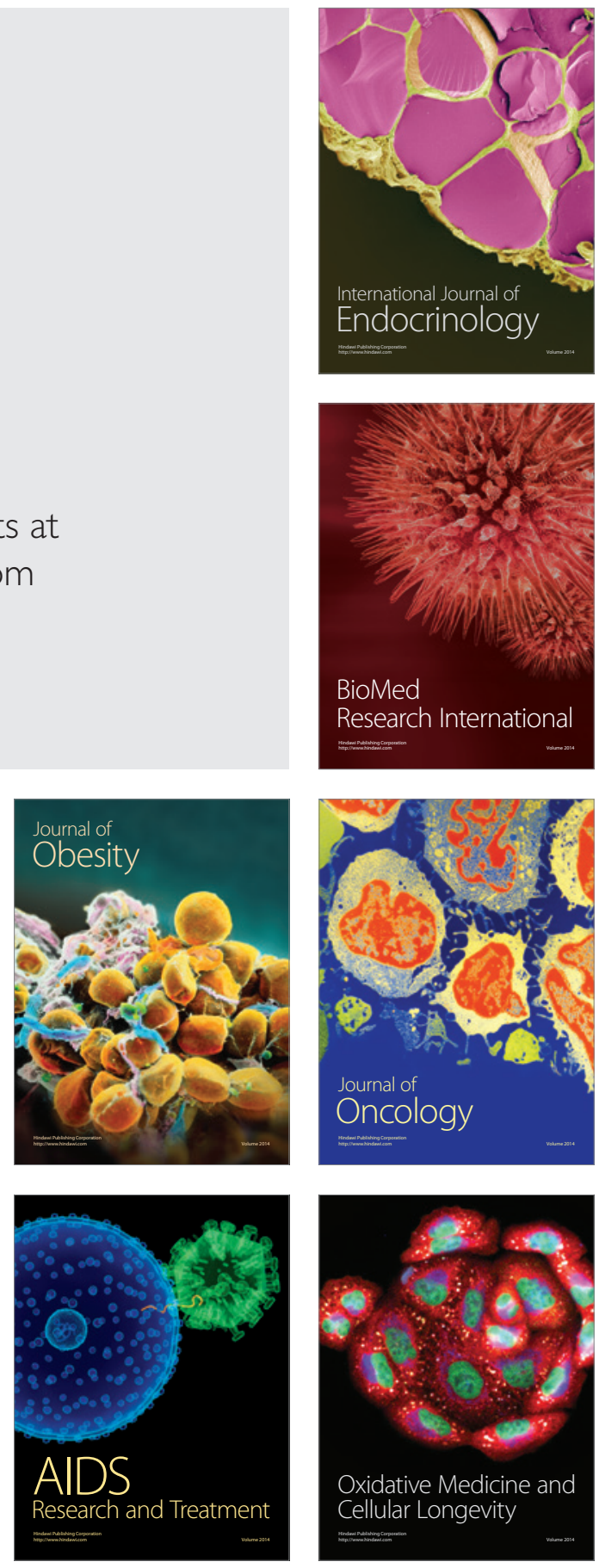